\title{
Increased alveolar nitric oxide concentration in asthmatic patients with nocturnal symptoms
}

\author{
L. Lehtimäki*,\#, H. Kankaanranta*,ף, S. Saarelainen`, V. Turjanmaa ${ }^{+}$, E. Moilanen*,\#
}

Increased alveolar nitric oxide concentration in asthmatic patients with nocturnal symptoms. L. Lehtimäki, H. Kankaanranta, S. Saarelainen, V. Turjanmaa, E. Moilanen. (C) ERS Journals Ltd 2002.

ABSTRACT: Nocturnal asthma symptoms and impaired lung function at night are related to inflammatory activity in the peripheral lung compartment. Exhaled nitric oxide (NO) measurement at multiple exhalation flow rates can be used to separately assess alveolar and bronchial NO production and inflammation. The authors hypothesised that asthmatic patients with nocturnal symptoms have a higher alveolar NO concentration than those with only daytime symptoms.

The authors asked 40 patients with newly-diagnosed steroid-naïve asthma about their nocturnal asthma symptoms through the use of a written questionnaire. Alveolar NO concentration and bronchial NO flux were assessed in the 40 asthmatics and 40 healthy controls.

Nineteen of the $\mathbf{4 0}$ patients reported nocturnal symptoms. Patients with nocturnal symptoms had a higher alveolar NO concentration $(1.7 \pm 0.3$ (mean \pm SEM) parts per billion (ppb)) than patients without nocturnal symptoms $(0.8 \pm 0.3 \mathrm{ppb}, \mathrm{p}=\mathbf{0 . 0 1 2})$ or healthy controls $(1.0 \pm 0.1 \mathrm{ppb}, \mathrm{p}=\mathbf{0 . 0 3 2})$. Bronchial NO flux was higher both in patients with $\left(2.4 \pm 0.4 \mathrm{~nL} \cdot \mathrm{s}^{-1}, \mathrm{p}<0.001\right)$ and without $\left(2.6 \pm 0.4 \mathrm{~nL} \cdot \mathrm{s}^{-1}, \mathrm{p}<0.001\right)$ nocturnal symptoms, compared to controls $\left(0.7 \pm 0.1 \mathrm{~nL} \cdot \mathrm{s}^{-1}\right)$.

Nocturnal symptoms in asthmatic patients are related to a higher alveolar nitric oxide concentration. The results suggest that assessment of alveolar nitric oxide concentration can be used to detect the parenchymal inflammation in asthmatic patients with nocturnal symptoms.

Eur Respir J 2002; 20: 841-845.
*The Immunopharmacological Research Group, Medical School, University of Tampere, Depts of ${ }^{\#}$ Clinical Chemistry, Respiratory Medicine and ${ }^{+}$Clinical Physiology, Tampere University Hospital, Tampere, Finland.

Correspondence: E. Moilanen, Medical School, FIN-33014 University of Tampere, Tampere, Finland.

Fax: 35832158082

E-mail: eeva.moilanen@uta.fi

Keywords: Asthma, bronchi, exhaled nitric oxide, inflammation, nocturnal, pulmonary alveoli

Received: January 152002

Accepted after revision: May 92002

The study was supported by grants from the National Technology Agency (Tekes), the Medical Research Fund of Tampere University Hospital, Tampere Tuberculosis Foundation, Jalmari and Rauha Ahokas Foundation, and the Academy of Finland.
Nocturnal symptoms and worsening of lung function at night are common among patients with asthma. Up to $74 \%$ of asthmatics have been reported to awaken at night at least once a week due to wheezing, chest tightness or cough [1]. Several factors, such as nocturnal increase in vagal tone or decrease in cortisol and epinephrine secretion, may underlie the pathogenesis of nocturnal asthma [2]. Nocturnal asthma has been associated with either nocturnal enhancement of airway inflammation or persistently increased inflammatory activity. Bronchial biopsies have not revealed significant differences in inflammation in central airways between nocturnal and nonnocturnal asthmatics [3, 4]. However, studies with techniques assessing more peripheral lung compartments (bronchoalveolar lavage (BAL) and transbronchial biopsies) have suggested enhanced night-time inflammation in nocturnal asthmatics compared with their daytime level $[3,5]$ or with night-time inflammation in non-nocturnal asthmatics [5, 6]. In contrast, some BAL studies suggest persistently more active inflammation in nocturnal than non-nocturnal asthma [7]. Inflammation in nocturnal asthma therefore seems to be enhanced in peripheral but not central lung compartments as compared with non-nocturnal asthma. However, the results on whether this difference is related to circadian rhythm are conflicting. There might also be differences in cellular composition of airway inflammation between nocturnal and non-nocturnal asthma, as airway neutrophilia has been found in severe persistent asthma $[8,9]$, which is often associated with increased nocturnal symptoms.

Exhaled nitric oxide (NO) concentration correlates with many aspects of inflammatory activity in asthmatic airways, and is considered to be a useful tool for noninvasively assessing airway inflammation [10, 11]. Exhaled NO has usually been measured at a single exhalation flow rate. However, more detailed information on the inflammatory process is gained by measuring exhaled NO at multiple exhalation flow rates, as this allows separate assessment of alveolar NO concentration and bronchial NO flux [12-15]. Earlier studies using this method report increased bronchial NO flux in asthma and increased alveolar NO concentration in alveolitis [13, 15-17].

The authors hypothesised that patients with nocturnal asthma symptoms have increased alveolar NO concentration in addition to increased bronchial NO flux, as enhanced peripheral inflammation has been associated with nocturnal asthma. Alveolar NO 
concentration and bronchial NO flux were studied in 40 patients with asthma, and their nocturnal symptoms were assessed with a written questionnaire. The authors also studied whether serum markers of inflammation suggest differences in activity or cellular composition of airway inflammation between asthmatics with and without nocturnal symptoms.

\section{Methods}

\section{Subjects}

Forty nonsmoking patients with newly-diagnosed steroid-naïve asthma were enrolled in the study. The diagnosis of asthma was based on typical symptoms and reversible or variable airflow obstruction [18, 19]. Forty healthy, nonsmoking subjects with normal spirometry and no bronchial hyperresponsiveness served as controls. Alveolar NO concentration and bronchial NO flux, lung function, nocturnal asthma symptoms and levels of inflammatory markers in serum were assessed in all subjects. Measurements were performed between 14:00-16:30 h. The study was approved by the Ethics Committee of Tampere University Hospital (Tampere, Finland), and all of the subjects gave written informed consent.

\section{Exhaled nitric oxide measurement}

Exhaled NO concentration was measured with a Sievers NOA 280 analyser (Sievers Instruments, Boulder, CO, USA). Three exhalation flow rates $\left(100,175\right.$ and $\left.370 \mathrm{~mL} \cdot \mathrm{s}^{-1}\right)$ were used with mouth pressure of $9 \mathrm{cmH}_{2} \mathrm{O}$, as previously described [17]. Alveolar NO concentration and bronchial NO flux were assessed as suggested by Tsoukias and George [12]. The analyser was calibrated daily with a known NO concentration (103 or 101 parts per million; AGA, Lidingö, Sweden) and before every subject with filtered NO-free air.

\section{Lung function and nocturnal symptoms}

Spirometry (Vmax 20C; SensorMedics, Yorba Linda, CA, USA) was measured and the results were compared with normal values in the Finnish population [20]. Bronchial responsiveness was studied by letting patients inhale increasing doses of methacholine and measuring spirometry after each dose [21]. Logarithm of the dose-response slope (per cent decline in forced expiratory volume in one second divided by the total dose of methacholine inhaled) was used in analysis [22]. As part of a written questionnaire [23], nocturnal asthma symptoms were assessed by asking whether cough, wheezing or shortness of breath had disturbed the patient's sleep during the last week [1].

\section{Allergy testing and inflammatory markers}

Atopy was tested with a skin-prick test. Eleven common animal and aeroallergens (ALK-Abello, Hørsholm, Denmark) were tested. A wheal diameter of $\geqslant 3 \mathrm{~mm}$ was considered a positive result. Serum levels of eosinophil protein X (EPX), eosinophil cationic protein (ECP), myeloperoxidase (MPO) and interleukin (IL)-6 were measured by immunoassay (EPX-radioimmunoassay (RIA), ECP-RIA and MPORIA: Pharmacia AB, Uppsala, Sweden; IL-6: PeliPair ELISA, CLB, Amsterdam, the Netherlands).

\section{Statistics}

All of the parameters were normally distributed (Kolmogorov-Smirnov test) and parametric tests were used. Differences between the three groups were analysed with analysis of variance and least significant difference (LSD) post-test. Results are presented as mean \pm SEM.

\section{Results}

Of the 40 patients with asthma, 19 patients reported nocturnal symptoms in the questionnaire and 21 had no nocturnal symptoms. Subject characteristics are given in table 1. Patients with nocturnal symptoms were on average somewhat older than patients without nocturnal symptoms. Sex distribution, proportion of atopic subjects and occurrence of bronchial hyperresponsiveness was similar in the two patient groups. There were no differences in lung function

Table 1. - Subject characteristics

\begin{tabular}{|c|c|c|c|c|c|c|c|c|c|}
\hline Group & $\begin{array}{c}\text { Subjects } \\
\mathrm{n}\end{array}$ & $\begin{array}{c}\text { Males } \\
\mathrm{n}\end{array}$ & $\begin{array}{l}\text { Age } \\
\text { yrs }\end{array}$ & $\begin{array}{c}\text { Atopics } \\
\mathrm{n}\end{array}$ & $\begin{array}{l}\text { FEV1 } \\
\% \text { pred }\end{array}$ & $\underset{\%}{\mathrm{FEV}_{1} / \mathrm{FVC}}$ & $\begin{array}{l}\text { FEF50 } \\
\% \text { pred }\end{array}$ & $\begin{array}{l}\beta_{2} \text {-induced } \\
\text { change in } \\
\text { FEV1 } \%\end{array}$ & Log DRS \\
\hline $\begin{array}{l}\text { Asthma } \\
\text { (NS) }\end{array}$ & 19 & 3 & $38 \pm 3^{+}$ & 11 & $93 \pm 2$ & $78 \pm 1^{\top}$ & $69 \pm 3$ & $7 \pm 1$ & $2.5 \pm 0.1^{\#}$ \\
\hline $\begin{array}{l}\text { Asthma } \\
\text { (no NS) }\end{array}$ & 21 & 5 & $28 \pm 2$ & 12 & $89 \pm 2$ & $79 \pm 2$ & $67 \pm 4$ & $8 \pm 1$ & $2.5 \pm 0.1^{\#}$ \\
\hline Control & 40 & 8 & $33 \pm 2$ & & $96 \pm 3$ & $84 \pm 1$ & $85 \pm 3$ & $3 \pm 1$ & $1.4 \pm 0.1$ \\
\hline
\end{tabular}

Data are presented as mean \pm SEM, unless otherwise indicated. NS: nocturnal symptoms; FEV1: forced expiratory volume in one second; FVC: forced vital capacity; FEF50: forced expiratory flow at 50\% of FVC; Log DRS: logarithm of the doseresponse slope of methacholine. ${ }^{\#}: \mathrm{p}<0.001$ compared with controls; ${ }^{\ominus}: \mathrm{p}<0.01$ compared with controls; ${ }^{+}: \mathrm{p}<0.05$ compared with asthmatics without NS. 

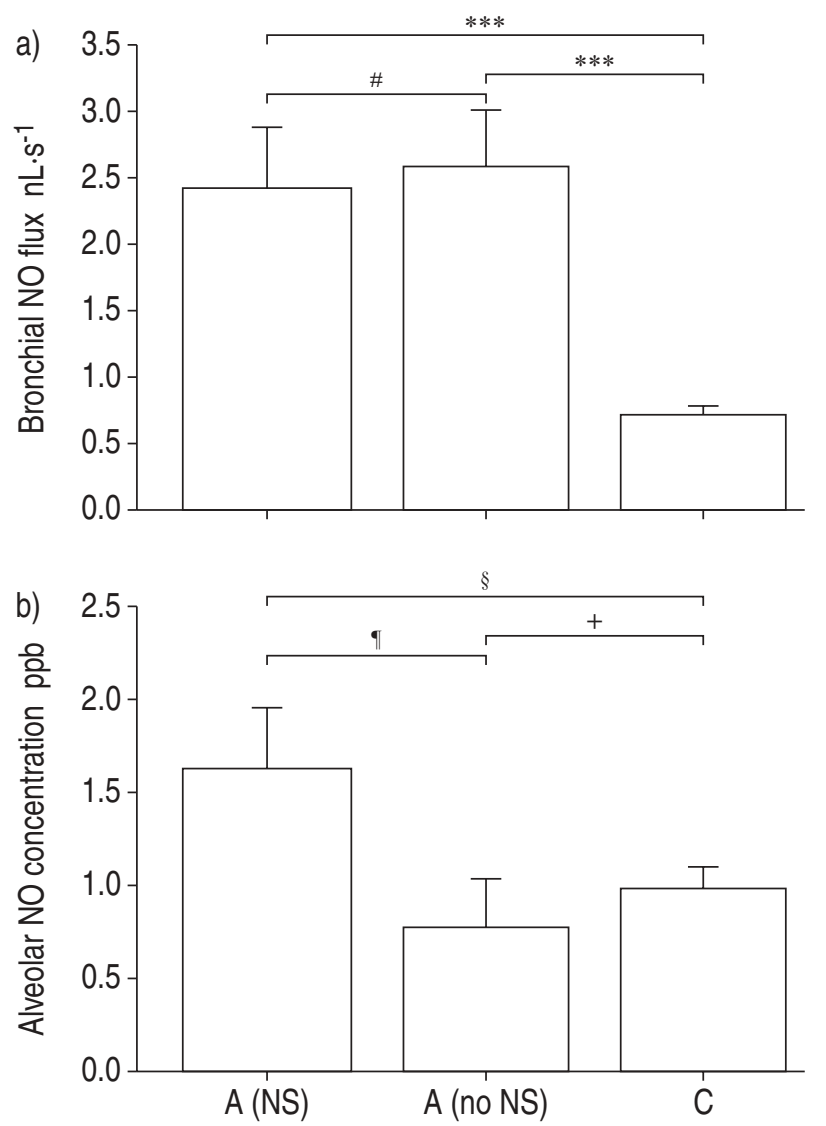

Fig. 1.-a) Bronchial nitric oxide (NO) flux $\left(\mathrm{nL} \cdot \mathrm{s}^{-1}\right)$ and b) alveolar NO concentration (parts per billion (ppb)) in 19 asthmatics with nocturnal symptoms (A (NS)), 21 asthmatics without nocturnal symptoms (A (no NS)) and 40 healthy controls (C). ${ }^{\#}: \mathrm{p}=0.284 ;{ }^{* * *}: \mathrm{p}<0.001 ;^{\uparrow}: \mathrm{p}=0.012 ;^{+}: \mathrm{p}=0.453 ;{ }^{\S}: \mathrm{p}=0.032$.

parameters between the patient groups, and both patient groups had impaired lung function compared to controls.

Patients with nocturnal symptoms had a higher alveolar NO concentration $(1.7 \pm 0.3$ parts per billion (ppb)) than patients without nocturnal symptoms $(0.8 \pm 0.3 \mathrm{ppb}, \mathrm{p}=0.012)$ or healthy controls $(1.0 \pm$ $0.1 \mathrm{ppb}, \mathrm{p}=0.032$ ). Bronchial NO flux was increased

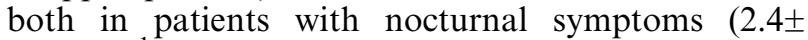
$\left.0.4 \mathrm{~nL} \cdot \mathrm{s}^{-1}, \mathrm{p}<0.001\right)$ and in patients without nocturnal

Table 2. - Inflammatory markers in serum

\begin{tabular}{llllc}
\hline Group & $\begin{array}{c}\mathrm{EPX} \\
\mu \mathrm{g} \cdot \mathrm{L}^{-1}\end{array}$ & $\begin{array}{c}\mathrm{ECP} \\
\mu \mathrm{g} \cdot \mathrm{L}^{-1}\end{array}$ & $\begin{array}{c}\mathrm{MPO} \\
\mu \mathrm{g} \cdot \mathrm{L}^{-1}\end{array}$ & $\begin{array}{c}\mathrm{IL}-6 \\
\mathrm{ng} \cdot \mathrm{L}^{-1}\end{array}$ \\
\hline $\begin{array}{c}\text { Asthma } \\
\text { (NS) }\end{array}$ & $41 \pm 5^{\bullet}$ & $18 \pm 3^{\#}$ & $302 \pm 45^{+}$ & $10 \pm 2^{\S}$ \\
$\begin{array}{c}\text { Asthma } \\
\text { (no NS) }\end{array}$ & $34 \pm 5^{\#}$ & $14 \pm 3$ & $205 \pm 21$ & $5 \pm 1$ \\
Control & $23 \pm 2$ & $11 \pm 1$ & $250 \pm 18$ & $5 \pm 1$ \\
\hline
\end{tabular}

Data are presented as mean \pm SEM. NS: nocturnal symptoms; EPX: eosinophil protein X; ECP: eosinophil cationic protein; MPO: myeloperoxidase; IL-6: interleukin-6. ${ }^{\#}: \mathrm{p}<0.05$ compared with controls; ${ }^{\uparrow}: \mathrm{p}<0.001$ compared with controls; ${ }^{+}: \mathrm{p}<0.05$ compared with asthmatics without NS; $\$$ : $\mathrm{p}<0.05$ compared with controls and asthmatics without NS. symptoms $\left(2.6 \pm 0.4 \mathrm{~nL} \cdot \mathrm{s}^{-1}, \mathrm{p}<0.001\right)$, as compared with controls $\left(0.7 \pm 0.1 \mathrm{~nL} \cdot \mathrm{s}^{-1}\right)$ (fig. 1$)$.

Serum EPX levels were higher in both patient groups than in healthy controls. The serum ECP level was increased only in patients with nocturnal symptoms, compared with controls. Patients with nocturnal symptoms had higher serum levels of MPO and IL-6 than patients without nocturnal symptoms (table 2).

\section{Discussion}

Alveolar NO concentration was increased in asthmatic patients with nocturnal symptoms but was normal in asthmatics without nocturnal symptoms. Bronchial NO flux was increased equally in both asthma groups. Serum levels of EPX were increased in both asthma groups, but patients with nocturnal symptoms had higher serum levels of MPO and IL-6 than patients without nocturnal symptoms.

The multiple exhalation flow rate method considerably improves exhaled NO measurement, as it allows separate assessment of inflammatory activity in alveolar and bronchial compartments. Increased bronchial NO flux has been reported in patients with asthma [13, 15-17], whereas alveolar NO concentration has been found to be increased in patients with alveolitis [15]. Anti-inflammatory treatment in asthma decreases bronchial NO flux, while in alveolitis, alveolar NO concentration decreases following the treatment [13, 15, 23].

There are two previous studies on nocturnal asthma and exhaled NO with somewhat conflicting results. TEN HACKen et al. [24] found a higher exhaled NO level in nocturnal asthmatics than in non-nocturnal asthmatics at a single higher exhalation flow rate $\left(167 \mathrm{~mL} \cdot \mathrm{s}^{-1}\right)$, whereas GEORGES et al. [25] did not find a significant difference in exhaled NO between such groups by using a lower exhalation flow rate $\left(80 \mathrm{~mL} \cdot \mathrm{s}^{-1}\right)$. Exhaled NO concentration at a single exhalation flow rate is a sum of both alveolar and bronchial NO sources, where bronchial NO predominates at lower flow rates while the contribution of alveolar NO increases with increasing flow rates [12]. In this sense, the previous results showing higher exhaled NO level in nocturnal than non-nocturnal asthmatics at a higher but not at a lower flow rate, are in line with the present results showing a higher alveolar NO concentration but similar bronchial NO flux in asthmatics with nocturnal symptoms compared with those without nocturnal symptoms. However, the present results are not directly comparable with the earlier studies because of differences in measurement technique.

The equally increased bronchial NO flux in the two asthma groups in the present study is consistent with the biopsy studies by KRAFT and coworkers $[3,6]$, which showed similar bronchial inflammatory activity in nocturnal and non-nocturnal asthmatics. In contrast, bronchial vascular inducible NO synthase (iNOS) expression was increased during the day in nocturnal asthmatics compared with non-nocturnal asthmatics [26]. However, changes in vascular iNOS expression might not affect NO concentration in 
exhaled air, as NO has a short half-life in tissue phase and probably does not diffuse from bronchial vessels to luminal air in high amounts. This is supported by the finding that exhaled NO concentration correlates with iNOS expression in airway epithelium but not with iNOS expression in lamina propria [27].

Although significant differences in central airway inflammation between nocturnal and non-nocturnal asthmatics have not been found [3, 4], increased inflammatory indices in BAL fluid and transbronchial biopsies from nocturnal asthmatics have been found. Some of these studies suggest persistently more active inflammation [7], whereas others suggest similar daytime but increased night-time inflammation in nocturnal asthma compared with non-nocturnal asthma [5, 6]. In the two-compartment model of pulmonary NO dynamics, alveolar compartment refers to alveoli and peripheral small airway units (respiratory bronchioles and airways smaller than these) [12]. Thus, the increased alveolar NO concentration in asthmatics with nocturnal symptoms in this study suggests that they also had inflammation in the distal lung units in addition to the equal bronchial inflammation seen in both asthma groups. The present results are therefore in line with earlier studies showing similar bronchial inflammation between nocturnal and non-nocturnal asthma, with the exception that nocturnal asthma is related to more active peripheral inflammation. Increased alveolar NO concentration during the daytime in patients with nocturnal symptoms supports the finding that nocturnal asthma is associated with higher daytime inflammatory activity. However, the diurnal variation in bronchial and alveolar NO parameters needs to be further assessed. Inter-study differences in patient selection (e.g. disease severity and medication) and definition of nocturnal asthma might affect the results obtained. While the present authors recruited patients with newly-diagnosed asthma without steroid treatment and based grouping on nocturnal symptoms, other studies have included patients with steroid treatment [7] and based grouping on circadian changes in peak expiratory flow rate $[3,7]$.

Serum levels of ECP or EPX were increased in both asthma groups and there was a tendency towards higher levels in asthmatics with nocturnal symptoms. This suggests that there is eosinophilic inflammation in both groups, and that it might be more active in patients with nocturnal symptoms. Levels of MPO and IL-6 were significantly higher in asthmatics with nocturnal symptoms than in those without nocturnal symptoms. An increased MPO level suggests that the patients with nocturnal symptoms also had neutrophilic activation, which is in line with a previous study that showed neutrophilic inflammation in severe asthma with frequent night-time symptoms [9]. IL-6 has a variety of pro- and anti-inflammatory roles and is produced in, for example, eosinophils and alveolar macrophages in asthmatic airways [28]. Enhanced asthmatic inflammation after naturally occurring asthmatic attack or allergen challenge increases circulating IL-6 levels [29]. Thus, the higher serum levels of IL-6 in patients with nocturnal symptoms may either reflect more active airway inflammation, as proposed in earlier studies [7], or suggest that the inflammation affects a larger airway area after spreading into peripheral lung units, as indicated by the higher alveolar NO concentration in these patients.

Asthmatic patients with nocturnal symptoms were on average older than patients without nocturnal symptoms. As there was no correlation between age and alveolar NO concentration in healthy subjects (Pearson's $\mathrm{r}=-0.08, \mathrm{p}=0.603$ ), age per se does not seem to explain the difference in alveolar NO concentration between the patient groups.

In conclusion, nocturnal asthma symptoms are related to increased alveolar nitric oxide concentration. This suggests that exhaled nitric oxide measurement at multiple flow rates could be used to assess the peripheral inflammation related to nocturnal asthma. The circadian variation in alveolar and bronchial nitric oxide production, and their relation to nocturnal worsening of lung function, needs to be clarified in future studies.

Acknowledgements. The authors would like to thank M-L. Lampén and P. Pirttimäki for their help with patient work, and H. Määttä for secretarial assistance.

\section{References}

1. Turner-Warwick M. Epidemiology of nocturnal asthma. Am J Med 1988; 85: 6-8.

2. Silkoff PE, Martin RJ. Pathophysiology of nocturnal asthma. Ann Allerg Asthma Im 1998; 81: 378-383.

3. Kraft M, Djukanovic R, Wilson S, Holgate ST, Martin RJ. Alveolar tissue inflammation in asthma. Am J Respir Crit Care Med 1996; 154: 1505-1510.

4. ten Hacken NH, Timens W, Smith M, Drok G, Kraan J, Postma DS. Increased peak expiratory flow variation in asthma: severe persistent increase but not nocturnal worsening of airway inflammation. Eur Respir J 1998; 12: 546-550.

5. Martin RJ, Cicutto LC, Smith HR, Ballard RD, Szefler SJ. Airways inflammation in nocturnal asthma. Am Rev Respir Dis 1991; 143: 351-357.

6. Kraft M, Martin RJ, Wilson S, Djukanovic R, Holgate ST. Lymphocyte and eosinophil influx into alveolar tissue in nocturnal asthma. Am J Respir Crit Care Med 1999; 159: 228-234.

7. Oosterhoff Y, Kauffman HF, Rutgers B, Zijlstra FJ, Koeter GH, Postma DS. Inflammatory cell number and mediators in bronchoalveolar lavage fluid and peripheral blood in subjects with asthma with increased nocturnal airways narrowing. $J$ Allergy Clin Immunol 1995; 96: 219-229.

8. Wenzel SE, Szefler SJ, Leung DY, Sloan SI, Rex MD, Martin RJ. Bronchoscopic evaluation of severe asthma. Persistent inflammation associated with high dose glucocorticoids. Am J Respir Crit Care Med 1997; 156: 737-743.

9. Jatakanon A, Uasuf C, Maziak W, Lim S, Chung KF, Barnes PJ. Neutrophilic inflammation in severe persistent asthma. Am J Respir Crit Care Med 1999; 160: $1532-1539$.

10. Silkoff PE. Noninvasive measurement of airway 
inflammation using exhaled nitric oxide and induced sputum. Clin Chest Med 2000; 21: 345-360.

11. Kharitonov SA, Barnes PJ. Exhaled markers of pulmonary disease. Am J Respir Crit Care Med 2001; 163: 1693-1722.

12. Tsoukias NM, George SC. A two-compartment model of pulmonary nitric oxide exchange dynamics. $J \mathrm{Appl}$ Physiol 1998; 85: 653-666.

13. Silkoff PE, Sylvester JT, Zamel N, Permutt S. Airway nitric oxide diffusion in asthma: Role in pulmonary function and bronchial responsiveness. Am $J$ Respir Crit Care Med 2000; 161: 1218-1228.

14. Jörres RA. Modelling the production of nitric oxide within the human airways. Eur Respir J 2000; 16: 555560 .

15. Lehtimäki L, Kankaanranta $\mathrm{H}$, Saarelainen $\mathrm{S}$, et al. Extended exhaled NO measurement differentiates between alveolar and bronchial inflammation. $\mathrm{Am}$ J Respir Crit Care Med 2001; 163: 1557-1561.

16. Högman $\mathrm{M}$, Lúdvíksdóttir $\mathrm{D}$, Anderson $\mathrm{SD}$, et al. Inhaled mannitol shifts exhaled nitric oxide in opposite directions in asthmatics and healthy subjects. Respir Physiol 2001; 124: 141-150.

17. Lehtimäki L, Turjanmaa V, Kankaanranta H, Saarelainen S, Hahtola P, Moilanen E. Increased bronchial nitric oxide production in patients with asthma measured with a novel method of different exhalation flow rates. Ann Med 2000; 32: 417-423.

18. National Heart Lung and Blood Institute. Guidelines for the diagnosis and management of asthma. NIH publication No. 97-4051, July 1997. Bethesda, MD, National Institutes of Health, 1997.

19. American Thoracic Society. Lung function testing: selection of reference values and interpretative strategies. Am Rev Respir Dis 1991; 144: 1202-1218.

20. Viljanen AA, Halttunen PK, Kreus KE, Viljanen BC.
Spirometric studies in non-smoking, healthy adults. Scand J Clin Lab Invest 1982; 42: Suppl. 159, 5-20.

21. Nieminen MM. Unimodal distribution of bronchial hyperresponsiveness to methacholine in asthmatic patients. Chest 1992; 102: 1537-1543.

22. O'Connor G, Sparrow D, Taylor D, Segal M, Weiss S. Analysis of dose-response curves to methacholine. An approach suitable for population studies. Am Rev Respir Dis 1987; 136: 1412-1417.

23. Lehtimäki L, Kankaanranta H, Saarelainen S, Turjanmaa V, Moilanen E. Inhaled fluticasone decreases bronchial but not alveolar nitric oxide output in asthma. Eur Respir $J$ 2001; 18: 635-639.

24. ten Hacken NH, van der Vaart H, van der Mark TW, Koeter GH, Postma DS. Exhaled nitric oxide is higher both at day and night in subjects with nocturnal asthma. Am J Respir Crit Care Med 1998; 158: 902907.

25. Georges G, Bartelson BB, Martin RJ, Silkoff PE. Circadian variation in exhaled nitric oxide in nocturnal asthma. J Asthma 1999; 36: 467-473.

26. ten Hacken NH, Postma DS, Drok G, Smith M, Kraan J, Timens W. Increased vascular expression of iNOS at day but not at night in asthmatic subjects with increased nocturnal airway obstruction. Eur Respir J 2000; 16: 445-451.

27. Gabbay E, Walters EH, Orsida B, et al. Post-lung transplant bronchiolitis obliterans syndrome (BOS) is characterized by increased exhaled nitric oxide levels and epithelial inducible nitric oxide synthase. $A m$ J Respir Crit Care Med 2000; 162: 2182-2187.

28. Chung KF, Barnes PJ. Cytokines in asthma. Thorax 1999; 54: 825-857.

29. Yokoyama A, Kohno N, Fujino S, et al. Circulating interleukin-6 levels in patients with bronchial asthma. Am J Respir Crit Care Med 1995; 151: 1354-1358. 